\title{
Desenvolvimento de Interfaces Digitais Infantis: Estudo Preliminar sobre Design Centrado na Criança
}

\section{Development of Digital Interfaces for Children: Preliminary Study on Child Centered Design}

\author{
Diogo Gonçalves Martins ${ }^{1}$ \\ Márcia Cattoi Schimidt ${ }^{2}$ \\ Ricardo Schwinn Rodrigues ${ }^{3}$ \\ Monique Vandersen ${ }^{4}$
}




\section{Resumo}

O Design Centrado no Usuário é uma das principais abordagens na contemporaneidade, mas sua aplicabilidade é comprometida pela dificuldade em delinear usuários. Particularidades individuais criam ruídos de usabilidade ainda mais perceptíveis em produtos que consideram usuários adultos e crianças. Visando a ampliação da discussão sobre interfaces com Design Centrado na Criança, por uma revisão bibliográfica, buscou-se vincular em infográfico os princípios para a criação de sistemas de visualização para interfaces, de Wickens et al. [2003], e os cinco tópicos principais levados em consideração no Design Centrado na Criança, de Idler [2014].

Palavras-chave: Design centrado na criança, interfaces digitais, usabilidade.

\section{Abstract}

User-Centered Design is one of the main approaches in the contemporaneity, but its applicability is compromised by the difficulty in delineating users. Individual peculiarities create even more noticeable usability noises in products that consider adult and children as users. Aiming to broaden the discussion about interfaces with Child-Centered Design, through a bibliographical review, we attempted to link in infographic the principles for the creation of visualization systems for interfaces, by Wickens et al. [2003], and the five major topics taken into account in Child-Centered Design, by Idler [2014].

Key-words: Child-centered design, digital interfaces, usability.

ISSN: 2316-7963

Mestrando, UDESC (diogo3martins@gmail.com)

${ }^{2}$ Mestre em Design, UDESC

${ }^{3}$ Mestre em Design, UDESC

${ }^{4}$ Doutora em Ciência da Comunicação, UDESC 


\section{Introdução}

Este trabalho tem o objetivo de fazer um levantamento teórico acerca de alguns fundamentos a respeito de interfaces digitais para crianças. $O$ cruzamento destas informações permite a criação de uma tabela que agrupa e categoriza as principais características do usuário infantil e princípios relacionados. O estudo parte da premissa do adulto ser usualmente considerado o "usuário padrão" e também no fato do design centrado no usuário infantil ser desenvolvido pelo entendimento que adultos têm da criança.

O trabalho inicia levantando questões sobre o Design Centrado no Usuário e suas principais características. Logo em seguida introduz o conceito de Design Centrado na Criança, de Idler [2014], apontando suas principais prerrogativas e algumas características que diferenciam o usuário infantil do adulto. Após, trata-se do conceito de interface e de que forma este conceito se coloca dentro da abordagem do Design Centrado no Usuário. Assim, são apresentados princípios para a criação de interfaces que têm como base a percepção e a cognição do usuário. Ao final deste cruzamento de conhecimentos se extrai um terceiro bloco de critérios que pode alimentar a discussão acerca da formulação de diretrizes para a criação de interfaces digitais para crianças.

\section{Design Centrado No Usuário}

Um dos principais conceitos do design contemporâneo é o de Design Centrado no Usuário (DCU), ou Design Centrado no Ser Humano (DCH). Este conceito baseia-se na ideia de que todo e qualquer processo de design precisa ter o usuário como origem e como finalidade na sua concepção e planejamento. Implica em participação ativa do usuário no processo, não apenas limitando a ele o papel de consumidor final ou público alvo, uma figura abstrata. Esta participação é fundamental ao processo de design, desde os estágios iniciais, porque faz com que o produto/serviço seja moldado às suas necessidades reais. No processo de DCU considera-se que o produto final foi concebido de acordo com especificações de um usuário padrão, mas que possui a predisposição de se moldar às características dos indivíduos de um complexo predefinido.

Segundo Norman [2006, p. 224-225] o Design Centrado no Usuário é aquele capaz de reunir produtos compreensíveis e facilmente utilizáveis através da simplificação de tarefas. Também reduzem possíveis erros, ao explorar de maneira adequada os modelos mentais do usuário. Ou seja, um modelo mental é desenvolvido pelo usuário e indica como uma interface deve ser utilizada a partir da interpretação dos elementos da interface. Para o autor, o design centrado no usuário tem o intuito de tornar equivalentes os modelos conceituais do designer e do usuário, através da interface do produto. Como o modelo conceitual do usuário determina o que é compreendido, o designer, portanto, deve fornecer modelos facilmente compreensíveis e usáveis, deixando claras as intenções funcionais da interface.

Em sua obra Methods to Support Human-Centred Design, Martin Maguire [2001] aponta os principais pontos para um processo de DCU: 
- "O envolvimento ativo dos usuários e o claro entendimento do usuário e dos requerimentos de função". O envolvimento do usuário no processo de design é importante para conhecer contextos reais de utilização. Também pode favorecer a aceitação do produto, sem parecer que lhe foi imposto.

- "Uma alocação apropriada da função entre usuário e produto". Uma vez que a interação envolve ações do usuário e da máquina, esta divisão laboral deve estar claramente estabelecida. Deve ter como foco a capacidade humana, suas limitações e um entendimento profundo dos verdadeiros atributos ou propriedades da função.

- "Iteração de soluções de planejamento". A concepção de um sistema iterativo tem origem no recebimento de respostas do usuário, pelo uso de protótipos em estágios iniciais do processo. O usuário testa a realização de funções reais no protótipo, resultando dados para utilização nas etapas posteriores de design.

- "Equipe Multidisciplinar de projetistas". Processos de DCH são processos colaborativos, que se beneficiam do envolvimento de stakeholders. O grupo de desenvolvedores pode ser composto de especialistas com habilidades técnicas. A equipe pode ser composta por gerentes, especialistas de usabilidade, usuários finais, engenheiros de software, designers gráficos, designers de interação, equipes de suporte e treinamento, e especialistas funcionais.

[MAGUIRE,2001, p. 02, tradução dos autores.]

Para o designer que aplica DCU, mais importante do que saber o que está criando, é saber para quem está criando. É preciso entender as necessidades deste usuário, suas aspirações com relação à experiência de uso do produto e principalmente as suas limitações, sejam elas físicas ou cognitivas. É nesta ótica que Sabina Idler [2014] propõe o conceito: Design Centrado na Criança, ou DCC. A autora é fundadora da empresa holandesa UX Kids, especializada em pesquisa e consultoria para aplicações do design focado na criança.

\section{Design Centrado Na Criança}

Idler [2014] buscou delinear o DCC identificando em sua pesquisa cinco pontos onde as crianças são diferentes dos adultos nas pesquisas e, por consequência, diferentes deste usuário padrão.

- "Desenvolvimento Físico": A coordenação olho-mão e coordenação motora fina das crianças são comprometidas em relação ao adulto, afetando a interação com os equipamentos. Também as métricas infantis, além de diferir das usadas para adultos, diferem entre si durante o crescimento. Todas as medidas (altura, mãos) interferem na utilização de equipamentos digitais, especialmente os sensíveis ao toque.

- "Desenvolvimento Cognitivo": As habilidades cognitivas estão em desenvolvimento na criança, afetando os métodos de coleta e os resultados de pesquisas. Seu raciocínio torna-se mais abstrato conforme a idade, abrindo-se para novas perspectivas.

- "Desenvolvimento Social": Crianças podem ser muito individualistas, mas a maturidade altera sua percepção do outro, a empatia e a personalidade.

- "Concentração": Crianças podem ser naturalmente estimuladas, mas podem 
desconcentrar-se com a mesma facilidade. É importante oferecer motivação suficiente para mantê-las interessadas.

- "Experiência": Crianças vivenciaram menos que adultos, e não estão treinadas a aplicar conhecimentos familiares a novas situações. Por isto é importante oferecer informações suficientes e não se basear em apenas suposições, pois haverá geração de incerteza e desencorajamento para a atividade proposta.

[IDLER, S., 2014, tradução dos autores].

Percebe-se que, independentemente da área do design, a criança não tem feito parte deste conjunto de características que identificam o "usuário padrão". A criança possui características próprias e verifica-se que estas podem fazer parte do repertório semântico e do processo de design de uma forma geral. Na construção de interfaces não poderia ser diferente, principalmente quando a interface em questão é para um dispositivo digital destinado à criança. Idler [2014] também propõe cinco tópicos principais para levar em consideração ao colocar a criança como foco no processo de design:

- Entretenimento: Diferente dos adultos, a maioria das crianças utilizam as mídias unicamente para o entretenimento, não para serem produtivas de alguma forma. Crianças esperam um alto índice de entretenimento, e para tal, seus índices de tolerância são bastante baixos. Isso significa que uma experiência lúdica e surpreendente atrairá mais o interesse infantil.

- Apelo visual: Enquanto adultos geralmente utilizam as mídias por motivos mais específicos, as crianças necessitam de algum tipo de influência externa. Tal motivação pode ser a indicação de um amigo ou o próprio design do aplicativo. Um design divertido e atrativo pode despertar a criatividade da criança e motivá-la a começar a utilizar o aplicativo. Após a utilização inicial, o apelo visual continua importante, mas não é o único critério para manter a atenção da criança. $O$ uso repetido depende da resposta positiva que o aplicativo suscita.

- Usabilidade: A usabilidade de aplicativos afeta diretamente a sua popularidade. Crianças contemporâneas cresceram com mídias digitais enquanto alguns adultos se sentem intimidados e duvidam de suas próprias habilidades. Crianças sempre culparão a mídia em questão, possuem pouca paciência e um baixo índice de tolerância. Se o aplicativo não funcionar da maneira que esperam, se não for intuitivo, geralmente elas não se darão ao trabalho de ler as instruções nem perderão tempo tentando descobrir. Aplicativos amigáveis são mais efetivos quando atendem às capacidades físicas e cognitivas, conforme a idade de seus usuários.

- Conteúdo apropriado à idade: Além do design gráfico e da usabilidade, o conteúdo tem um papel importante na criação de mídias digitais relevantes para crianças. O conteúdo deve combinar com os interesses naturais e modelos mentais para a idade dos usuários. Conteúdos que forem muito simples serão considerados tediosos, enquanto os muito complexos, inviáveis. Considerando o rápido desenvolvimento de crianças abaixo dos doze anos de idade, é crítico para qualquer bom aplicativo focar-se em um grupo de idade específico. Se mais de um grupo de idade for considerado, é oportuno oferecer diferentes níveis de complexidade.

- Aprendizado incentivado: Crianças são curiosas por natureza. Elas querem 
aprender, e querem aprender brincando. Mídias digitais oferecem possibilidades praticamente ilimitadas de ensinar ludicamente. Conteúdo novo e atrativo torna o aplicativo divertido e cativante. É importante atender às habilidades do seu estágio de desenvolvimento. Para um uso mais prolongado, pode ser indicado oferecer diferentes níveis com novos desafios para manter o estímulo.

[IDLER, S., 2014, tradução dos autores].

Quanto às questões de conteúdo apropriado e estágio de desenvolvimento, destacamos a Teoria de Estágios de Desenvolvimento Cognitivo de Piaget [1999]. O autor considera o desenvolvimento psíquico um processo constante de equilibração, do nascimento até o estágio adulto. Relaciona-se com a maturidade dos órgãos e sistematização do raciocínio, e também é perceptível nas relações afetivas e sociais. A Tabela 1 contém os seis estágios pesquisados por Piaget:

\begin{tabular}{|c|c|c|}
\hline \multirow{3}{*}{$\begin{array}{l}0 \text { a } 2 \text { ou } 2,5 \\
\text { anos }\end{array}$} & $\begin{array}{c}1^{\circ} \\
\text { ESTÁGIO }\end{array}$ & $\begin{array}{l}\text { Estágio dos reflexos, mecanismos h ereditários, } \\
\text { tendências instintivas (nutrição) e primeiras emoções. }\end{array}$ \\
\hline & $\begin{array}{l}2^{\circ} \\
\text { ESTÁGIO }\end{array}$ & $\begin{array}{l}\text { Estágio dos primeiros: } \mathrm{h} \text { ábitos } \mathrm{m} \text { otores, percepções } \\
\text { organizadas e sentimentos diferenciados. }\end{array}$ \\
\hline & $\begin{array}{l}3^{\circ} \\
\text { ESTÁGIO }\end{array}$ & $\begin{array}{l}\text { Estágio da inteligência senso-motora ou prática (anterior } \\
\text { à linguagem), regulações a fetivas elementares, } \\
\text { primeiras fixações exteriores da afetividade. }\end{array}$ \\
\hline 2 a 7 anos & $\begin{array}{c}4^{\circ} \\
\text { ESTÁGIO }\end{array}$ & $\begin{array}{l}\text { Estágio da i nteligência intuitiva, s entimentos } \\
\text { interindividuais espontâneos e submissão ao adulto. }\end{array}$ \\
\hline $\begin{array}{l}7 \text { a } 11 \text { o u } 12 \\
\text { anos }\end{array}$ & $\begin{array}{l}5^{\circ} \\
\text { ESTÁGIO }\end{array}$ & $\begin{array}{l}\text { Estágio das operações intelectuais c oncretas, começo } \\
\text { da lógica e sentimentos morais e sociais de cooperação. }\end{array}$ \\
\hline Adolescência & $\begin{array}{l}6^{\circ} \\
\text { ESTÁGIO }\end{array}$ & $\begin{array}{l}\text { Estágio das operações intelectuais abstratas, formação } \\
\text { da p ersonalidade e i nserção afetiva e intelectual na } \\
\text { sociedade dos adultos. }\end{array}$ \\
\hline
\end{tabular}

O autor ressalta que as ações, diante de um questionamento ou problema, supõem sempre interesses que as desencadeiam. As funções do interesse são invariáveis, mas "os interesses" e "as explicações" variam com as idades. [PIAGET, 1999, p. 14]. Assim, também variam as formas de organização da atividade mental (motora, intelectual e afetiva).

Os estágios não são fixos rigidamente, mas podem indicar conteúdos e níveis de complexidades para cada faixa etária, pois se caracterizam pelo surgimento de estruturas originais distintas do estágio precedente.

\section{Interfaces Digitais}

Segundo Santa Rosa e Moraes [2012], a interação humana com o computador corresponde a um campo interdisciplinar que tem como propósito geral compreender o uso (ou não uso) da tecnologia da informação pelas pessoas. Focando a satisfação do usuário e eficácia dos sistemas, engloba o ato de desenvolver, implantar e utilizar sistemas computacionais interativos, e também entender como isto afeta a 
sociedade. Segundo os autores, com os avanços tecnológicos ampliaram-se os estudos da psicologia cognitiva e a adaptação deste conhecimento em projetos com estratégias interativas foi impulsionada.

Uma das principais características de um jogo é a sua interatividade, válido para qualquer modelo, analógico ou digital. Portanto, se imaginarmos jogos e aplicativos digitais como sistemas de interação, para garantir eficiência e satisfação do usuário, é preciso observá-los sob a ótica da ergonomia. Tradicionalmente, o foco da ergonomia aplicada ao design está na melhora da usabilidade de interfaces, e fundamentalmente, no estabelecimento de interpretações quantitativas de seus aspectos (eficiência, eficácia e satisfação). Por exemplo, quantidade de erros por tarefa, tempo de finalização de tarefas, entre outros. [GREEN; JORDAN, 1999] Mais especificamente, como um processo de design de interação, onde se considera os atributos da máquina (capacidade de armazenamento, cálculos) e dos humanos (tarefas criativas, decisões) [SANTA ROSA E MORAES, 2012].

Avaliar o tema sob a ótica da ergonomia é ampliar a abrangência de aspectos como a questão visual dos monitores. São fontes reflexivas de energia luminosa, interferindo na experiência e conforto visuais, e também, em questões mais específicas como a capacidade de processamento de informações [PREECE ET AL, 2005]. Interagir é experimentar, criar vínculo e ainda, comunicar-se.

Uma preocupação central do Design de Interação é desenvolver produtos inte-
rativos que sejam utilizáveis, o que genericamente significa produtos fáceis de
aprender, eficazes no uso, que proporcionem ao usuário uma experiência agradá-
vel. Um bom ponto de partida para pensar sobre como projetar produtos intera-
tivos utilizáveis consiste em comparar bons e maus exemplos. Mediante a iden-
tificação de pontos fortes e fracos específicos de sistemas interativos diferentes,
podemos começar a entender o que quer dizer algo ser usável ou não. [PREECE
ET AL., 2005, p. 24]

Wickens et al. [2003], em seu livro An Introduction to Human Factors Engineering, definiram treze princípios para a criação de sistemas de visualização que podemos empregar na criação de interfaces. Estes princípios levam em consideração a percepção humana e o seu processamento de informações para criar interfaces de design capazes de gerar: redução de erros, de tempo requerido para treinamento, crescimento em eficiência e satisfação do usuário - são apenas alguns benefícios potenciais.

Estes princípios são divididos em quatro grandes grupos para uma melhor classificação, conforme Tabela 2. 


\section{PRINCÍPIOS BASEADOS NA PERCEPÇÃO}

1. Tornar a interface legível (ou audível)

2. Evitar julgamento de limites absolutos

3. Processamento
decrescente
A legibilidade da interface é crítica e necessária para a usabilidade. Se os caracteres ou objetos mostrados não puderem ser discerníveis, então, o usuário não poderá fazer um uso efetivo dos mesmos.

Não pedir ao usuário para determinar o nível de uma variável tendo como base apenas uma variável sensorial (como cor, tamanho, volume). Tais variáveis sensoriais podem conter inúmeros níveis possíveis.

Sinais são percebidos e interpretados em concordância com a experiência esperada de um usuário. Se um sinal é apresentado contrariamente ao que o usuário espera, uma maior quantidade de evidências físicas será necessária para assegurar que o usuário entendeu o sinal corretamente.

4. Ganho por redundância

Se um sinal é apresentado mais de uma vez, é mais provável que ele seja entendido corretamente. Este pode ser produzido apresentando-se o sinal de formas alternativas (como cor e formato, voz e impressão, etc.), já que redundância não significa repetição. Exemplo de redundância: placa de trânsito, onde as cores e as posições são as mesmas, variam os formatos.

Sinais semelhantes provavelmente causarão confusão. A intensidade de características similares em contraste com características diferentes gera signos mais similares. Características similares desnecessárias devem ser eliminadas e as diferenças devem ser ressaltadas.

\section{PRINCÍPIOS DE MODELOS MENTAIS}

Uma representação deve ser semelhante à variável que ela representa (como a alta temperatura em um termômetro deve ser mostrada como uma barra vertical crescente). Se existirem múltiplos elementos, eles devem estar configurados de forma semelhante a que estão em seu ambiente original.

7. Princípio da parte móvel

Elementos móveis devem mover-se em um padrão compatível com a maneira que o modelo mental do usuário se comporta no sistema. Por exemplo, o elemento móvel de um altímetro deve mover-se para cima, em altitude crescente. 


\section{PRINCÍPIOS BASEADOS NA ATENÇÃO}

8. Diminuição do custo de acesso à informação
Quando a atenção do usuário é desviada de um local a outro para acessar a informação necessária, existe um custo associado de tempo e esforço. O design da interface deve minimizar este custo permitindo que fontes acessadas com frequência fiquem na posição mais próxima possível. Entretanto, legibilidade nunca deve ser sacrificada para este fim.

Ter a atenção dividida por duas fontes de informação pode ser necessário para se completar uma tarefa. Estas fontes devem estar mentalmente integradas. O custo de acesso à informação deve ser baixo, o que pode ser alcançado de várias formas: por proximidade, ligadas por cores, padrões, formas, etc. Porém, o agrupamento de vários objetos pode sobrecarregar o layout da interface.

10. Princípio dos recursos múltiplos

O usuário processa melhor a informação que lhe é apresentada através de diferentes recursos. Por exemplo, uma informação apresentada de forma visual e auditiva simultaneamente, será processada melhor do que se for toda visual ou toda auditiva.

\section{PRINCÍPIOS DE MEMÓRIA}

11. Substituir memória
por informação
visual

12. Princípio da ajuda preditiva
Um usuário não deve precisar reter informações relevantes apenas em sua memória. Um menu, um checklist, ou algum outro tipo de representação pode auxiliar o usuário a memorizar. Entretanto, o uso da memória pode, em alguns casos, ajudar o usuário, eliminando a necessidade de acessar informação estritamente visual na interface. Por exemplo, as teclas de atalho facilitam o trabalho de um usuário experiente. Assim, o uso de ambos deve ser balanceado para se alcançar um design eficiente.

Ações proativas são geralmente mais eficazes do que ações reativas. Uma interface deve eliminar ações que demandem sobrecarga cognitiva por outras facilmente perceptíveis, reduzindo assim o uso de recursos mentais do usuário. Isto permitirá ao usuário a não apenas permanecer focado nas condições atuais, mas também a pensar em condições futuras. Exemplo: uma placa rodoviária que mostra a distância para determinados destinos.

\section{Princípio da consistência}

Velhos hábitos adquiridos em interfaces mais antigas podem facilmente migrar para suportar o processamento de informações em interfaces mais novas. A memória de longo prazo do usuário ativará ações que considerarem apropriadas. Um designer deve aceitar este fato e utilizar-se da consistência entre diferentes interfaces.

Tabela 2 - Princípios para a criação de sistemas de visualização para interfaces, criados por Wickens et al. [2003], Tabela elaborada pelos autores, tradução dos autores.

\section{Considerações Finais}

As informações aqui compiladas visam à construção de um cenário teórico e auxiliam na reflexão sobre o desenvolvimento de interfaces voltadas ao público infantil. Vislumbrando a necessidade de se estabelecer diretrizes básicas na criação de 
interfaces especificamente para crianças, destacam-se as cinco características básicas para o DCC de Idler [2014], e os treze princípios para a criação de sistemas de visualização de Wickens et al [2003].

De acordo com estes dois conjuntos de informações, elaborou-se um cruzamento entre eles para que se possa chegar a um panorama elementar de relações na criação de interfaces digitais para crianças. A concepção do Gráfico1 apenas sistematiza os dados para análise, necessitando mais aprofundamento, sobretudo no que tange às capacidades cognitivas da criança em seus diferentes estágios de desenvolvimento.

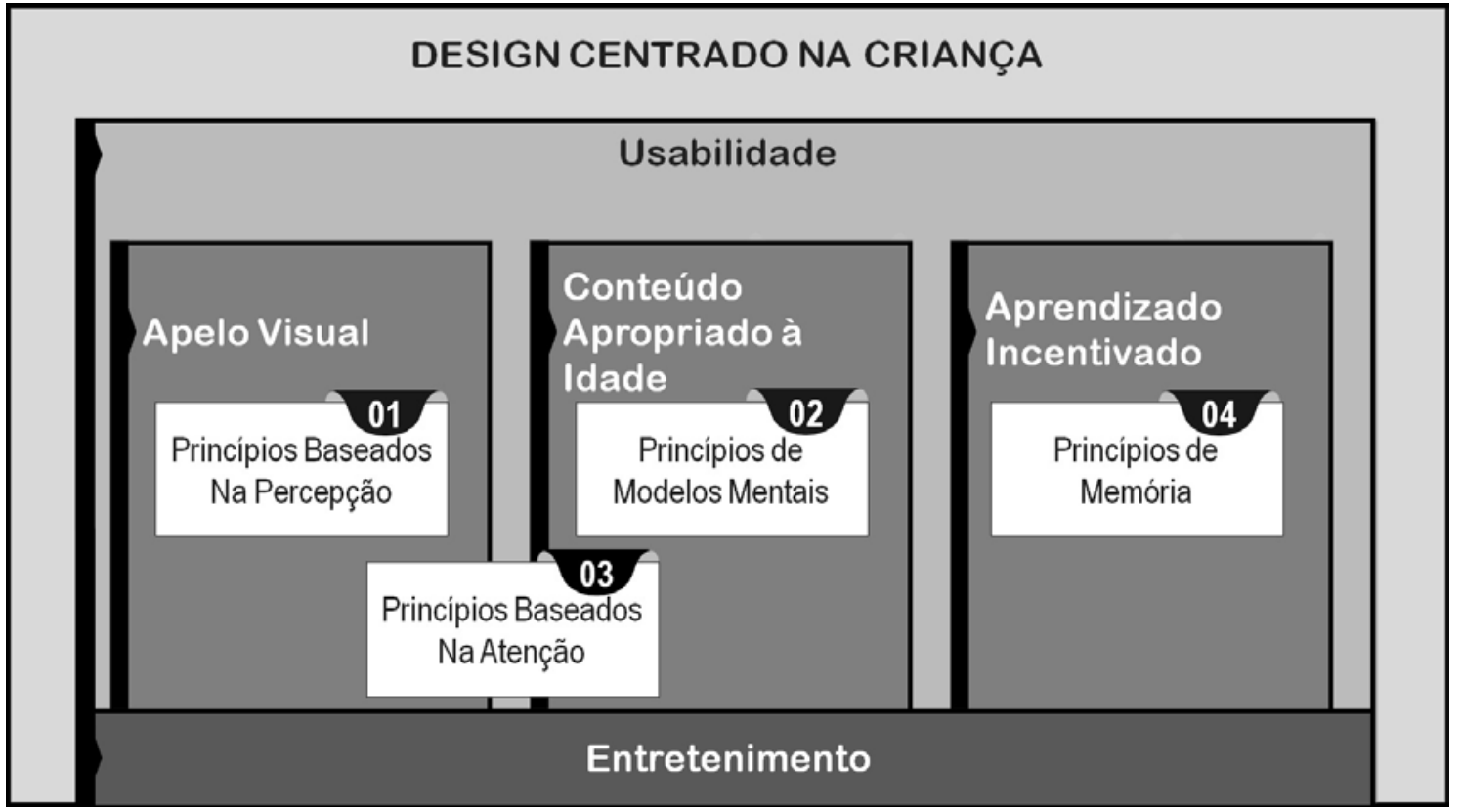

Legenda enumerada:

\section{PRINCÍPIOS BASEADOS NA PERCEPÇÃO}

Torne a interface legível (ou audível) Evite julgamento de limites absolutos Processamento decrescente Ganho por redundância Similaridade causa confusão: Use elementos distintos

\section{PRINCÍPIOS DE MODELOS MENTAIS}

Princípio da realidade pictorial Princípio da parte móvel

\section{PRINCÍPIOS BASEADOS NA ATENÇÃO}

Diminuição do custo de acesso à informação

Princípio da compatibilidade por aproximação

Princípio dos recursos múltiplos

\section{PRINCÍPIOS DE MEMÓRIA}

Substituir memória por informação visual

Princípio da ajuda preditiva

Princípio da consistência

Gráfico 1: Relações entre as cinco características do DCC de Idler [2014], e os princípios para a criação de sistemas de visualização, de Wickens et al [2003]. Infográfico elaborado pelos autores.

O Gráfico1 resulta da relação entre cinco características básicas levantadas por Idler [2014] em suas pesquisas com DCC, com os princípios de Wickens et al [2003], voltadas a qualquer usuário de equipamento digital. Verificou-se que há uma hierar- 
quização dos tópicos apontados e que os princípios estão contidos nestes tópicos, aqui representados graficamente.

Primeiramente, temos o processo de DCC, que engloba todos os outros princípios e conceitos, sendo assim a base para a discussão. O item "Usabilidade" concentra-se principalmente na experiência do usuário, na ergonomia, e por isso envolve todos os princípios e os valores (exceto "Entretenimento") apontados pelas duas fontes, pois se considera que uma boa experiência depende da sua consideração. Quanto ao item "Entretenimento", todos os aspectos estudados com foco no usuário infantil apontam especialmente para a valorização da experiência lúdica, sendo a ludicidade um valor destacado como essencial neste tipo de interação. Na Tabela 3 aparece como a base da interação. Ele não está vinculado diretamente aos princípios estudados, pois seu caráter é subjetivo, não é mensurável e não contribui para a legibilidade ou eficiência do sistema. Entretanto, a presença de elementos que favorecem a diversão, o jogo, o lazer, são apontados por Idler [2014], a partir de suas pesquisas, como a motivação para a aproximação e manutenção do interesse da criança com os dispositivos digitais.

"Apelo Visual" trata de Princípios baseados na Atenção e Percepção, já que estão vinculados com aspectos visuais, estéticos, considerados atrativos e significativos à criança, mas também com aspectos de legibilidade, facilidade de acesso aos dados, entre outros, ligados à visualidade. "Conteúdo Apropriado à Idade" está vinculado com Princípios que são baseados na Atenção, e de Modelos Mentais. Considera os estágios de desenvolvimento cognitivo da criança, principalmente aqueles ligados à compreensão, inteligibilidade do sistema, deste não estar sobrecarregado de linguagens comunicativas, por exemplo. ("Princípio dos Recursos Múltiplos"). "Aprendizado Incentivado" diz respeito à atratividade da interação e contém os "Princípios da Memória", uma vez que busca potencializar os recursos mentais do usuário e ser consistente nas diferentes versões do sistema. Também favorece a utilização do sistema através de conteúdos convidativos à criança.

A usabilidade de um produto destinado à criança não deve ser apenas presumida pela equipe de desenvolvimento, restringindo-se simplesmente à tarefa de traçar os resultados esperados e alguns parâmetros (geralmente ludicidade e apresentação de conteúdo apropriado à infância). Especialmente em projetos com abordagem DCC. Conforme exposto, há muitas outras questões a considerar, como legibilidade, usabilidade, complexidade de conteúdos para usuários diferentes, entre outras. Visando uma abordagem DCC, sempre que possível, os testes de usabilidade com protótipos deveriam ser aplicados, especialmente os baseados em observação e coleta de dados (por exemplo, expressão facial, tempo de uso, número de erros, entre outros). Crianças pequenas não conseguem verbalizar claramente o que estão pensando, de forma que estes testes fornecem informações sobre como a criança interage com o dispositivo digital, seja hardware e/ou software.

É importante ressaltar que todo objeto construído, analógico ou digital, para trabalho ou para entretenimento, promove interação humana desde seu projeto até o uso efetivo. Perceber um artefato implica na sua significação, mesmo que não seja a idealizada pelo designer, já que a significação diz respeito à experiência prévia e condição sociocultural. Com isso, podemos dizer que o DCC pode acolher e potenciali- 
zar aspectos culturais da criança, buscando reações de identidade, ou seja, portando aspectos que signifiquem algo para o usuário, sem perder seu caráter ergonômico. Se a criança participar do desenvolvimento, mais fácil será de identificar preferências, interesses, entendimentos e motivações.

Com a inclusão digital, o contato humano com equipamentos tecnológicos ocorre cada dia mais cedo. Conhecer características e interesses do usuário é requisito mínimo para os designers, já que os lançamentos de novos produtos envolvem muito capital pelo lado empresarial, e uma série de resultados satisfatórios ou insatisfatórios pela perspectiva do usuário. Para evitar perdas em ambos os lados, muitos pesquisadores traçaram diretrizes para o design de interfaces como se verificou, entre muitas outras não abordadas, podendo ser agrupadas em alguns parâmetros basilares que apontam para o usuário, e sua consequente satisfação.

\section{REFERÊNCIAS}

GREEN, W. S; JORDAN, Patrick W. Human factors in product design: current practice and future trends. Boca Raton, Fl: Taylor \& Francis, c1999.

IDLER, S. UXKids. 2013/2014. <Disponível em: http://uxkids.com/blog>. Acesso em: janeiro/2016.

MAGUIRE, M. Methods to support human-centered design. International Journey of Human-Computer Studies. (2001).

NORMAN, Donald A. O design do dia-a-dia. Rio de Janeiro: Rocco, 2006.

PIAGET, J. Seis estudos de Psicologia. 24 Ed. Rio de Janeiro: Forense Universitária, 1999.

PREECE, J.; ROGERS, Y.; SHARP, H. Design de Interação: além da interação homem-computador. Porto Alegre: Bookman, 2005.

SANTA ROSA, J. G.; MORAES, A. Avaliação e Projeto no Design de Interfaces. Teresópolis: 2ab Editora, 2012.

WICKENS, C. D.; LEE, John D.; LIU, Yili; GORDON-BECKER, Sallie. Introduction to Human Factors Engineering. 2nd Ed. Prentice Hall. 2003.

\section{Agradecimentos}

Gostaríamos de agradecer à Universidade do Estado de Santa Catarina (UDESC), ao Programa de Pós Graduação em Design - PPGDesign (UDESC) e à CAPES pelo apoio durante a realização dessa pesquisa. 